\title{
RESPONSIVENESS PENANGGULANGAN DAN PEMULIHAN PENCEMARAN LIMBAH INDUSTRI PADA LAHAN PERTANIAN DI KAWASAN RANCAEKEK
}

\section{RESPONSIVENESS OF INDUSTRIAL WASTE POLLUTION MITIGATION AND RECOVERY ON AGRICULTURAL LAND IN RANCAEKEK}

\author{
Rizki Nugraha; Budiman Rusli; MD. Enjat M \\ rizkinugraha2293@gmail.com; budiman.rusli@unpad.ac.id; mdenjatm@unpad.ac.id \\ Program Studi Administrasi Publik \\ Fakultas Ilmu Sosial Dan Ilmu Politik \\ Universitas Padjadjaran \\ Bandung, Indonsia
}

\begin{abstract}
ABSTRAK
Penelitian ini dilatarbelakangi oleh fenomena transformasi struktural dari pertanian ke industri, tanpa dibarengi dengan orientasi terhadap lingkungan hidup, sehingga terjadi pencemaran lingkungan akibat limbah industri terjadi pada lahan pertanian di Kawasan Rancaekek sejak 1991. Teori yang digunakan dalam penelitian ini adalah teori responsiveness dari Ansoff (1990) dan McDonnell yang diuraikan lebih lanjut oleh Popescu (2014). Metode penelitian kualitatif dipakai oleh penulis untuk mengatahui secara mendalam mengapa responsiveness penanggulangan dan pemulihan pencemaran limbah industri pada lahan pertanian di Kawasan Rancaekek kurang baik.

Hasil penelitian menunjukkan bahwa responsiveness Badan Pengelolaan Lingkungan Hidup Daerah Provinsi (BPLHD) Jawa Barat, Badan Pengendalian Lingkungan Hidup (BPLH) Kabupaten Bandung, dan Badan Lingkungan Hidup (BLH) Kabupaten Sumedang dalam penanggulangan dan pemulihan lahan tercemar kurang baik karena masih adanya pengaruh dari lingkungan Badan, belum adanya pedoman yang disepakati antar Badan, dan secara kapasitas belum memadai. Berdasar hal tersebut seharusnya ketiga Badan membuat SOP dan desain solusi yang disepakati bersama, menata ulang data dan laporan terkait permasalahan, dan melibatkan masyarakat dalam penyelesaian masalah yang ada.
\end{abstract}

Kata Kunci: Responsiveness, Penanggulangan dan Pemulihan, Pencemaran, Limbah industri.

\section{ABSTRACT}

This research is motivated by the phenomenon of structural transformation from agriculture to industry, without accompanied the orientation to the environment, so that happened environment pollution caused by industrial waste occurs on agricultural land in Rancaekek since 1991. The theory used in this research is the theory of responsiveness from Ansoff and McDonnell (1990) that elaborated more by Popescu (2014). Qualitative research methods used by the writer to understand in depth why the mitigation and recovery of industrial waste pollution on agricultural land responsiveness in Rancaekek is less good.

The research results showed that the responsiveness of The Local Environmental Management Agency Of West Java Province (BPLHD), The Environmental Control Agency Of Bandung Regency (BPLH), and The Environment Agency Of Sumedang Regency (BLH) in mitigation and recovery of contaminated land is less good because it is still the influence from the environment of Agency, the absence of guidelines that agreed between the Agency and the capacity is not yet adequate. Based on the case, the three agencies supposed to 
create SOP and solution design a mutually agreed, rearranging the data and reports related to the problem, and involve the community in solving problems.

Keywords: Responsiveness, Mitigation and Recovery, Pollution, Industrial Waste.

\section{PENDAHULUAN}

Fenomena transformasi struktural dari pertanian ke industri, membuat banyak lahan pertanian, Ruang Terbuka Hijau (RTH) terkonversi menjadi lahan industri. Kondisi seperti ini menyebabkan munculnya eksternalitas, baik positif maupun negatif. Eksternalitas positif yang paling dirasakan berkaitan dengan lapangan kerja. Namun adanya sisi positif itu tidak dibarengi dengan orientasi terhadap lingkungan hidup, sehingga eksternalitas negatif yang paling dirasakan yakni persoalan limbah menjadi ancaman yang tidak hanya untuk saat ini, tapi dapat pula menjadi masalah yang lebih serius lagi di masa yang akan datang. Disinilah diperlukan peran dari pemerintah untuk mengurus dan merespon eksternalitas yang ada, terlebih jika eksternalitas negatif berupa limbah sudah lintas wilayah administratif.

Otonomi daerah membuat pemerintah daerah memiliki kewenangan untuk menjalankan roda pemerintahannya, memenuhi kebutuhan daerahnya sendiri. Kenyataannya otonomi daerah disikapi beragam. Kabupaten atau kota cenderung memproteksi seluruh potensinya demi kepentingannya sendiri, dan menutup diri terhadap kabupaten atau kota lain. Dampak negatif kegiatan ekonomi di suatu daerah pada daerah lain, seperti externalities, juga tidak dihiraukan lagi (Keban, 2009).

Adanya eksternalistas negatif, seperti limbah industri, dari suatu daerah pada daerah lain tentu memerlukan responsiveness pemerintah daerah yang saling berkaitan agar dampak negatif tersebut dapat dikendalikan sesuai dengan regulasi yang ada. Namun faktanya eksternalitas negatif sangat sulit dikendalikan, terlebih jika sudah lintas administratif. Hal ini terjadi di Kawasan
Rancaekek, pencemaran terjadi dengan wilayah terdampak pencemaran berada di Kabupaten Bandung, sedangkan sumber pencemarnya adalah pelaku usaha yang masuk dalam wilayah administratif Kabupaten Sumedang

Pencemaran limbah dan kerusakan lingkungan di Rancaekek sudah terjadi lebih dari 20 tahun lamanya, tepatnya mulai dari tahun 1991, khususnya di 4 (empat) desa, yang masuk dalam administratif Kabupaten Bandung, yakni Desa Jelengong, Linggar, Bojongloa dan Sukamulya. Menurut Greenpace.org (2015) dan BPS Kabupatn Bandung (2015) tercatat kurang lebih 93 industri yang berdiri di Wilayah Rancaekek. Industri-industri yang ada menghasilkan limbah cair dengan total lebih dari 959 litek/detik atau 7,31 ton/hari.

Dari puluhan perusahaan di Kawasan Rancaekek justru perusahaan yang berada di administratif Kabupaten Sumedang yang dianggap menjadi penyumbang limbah terbanyak, terutama PT. Kahatex II, yang menyumbang debit limbah cair sebanyak 21.108 meter kubik perhari, ditambah PT. Five Star setidaknya 600 meter kubik pehari, dan PT. Insan Sandang mencapai 1500 meter kubik perhari, maka total ketiga perusahaan tersebut menyumbang debit limbah sebanyak 33,74\% dari debit total $65.618-$ 85.618 meter kubik perharinya. (BPLHD Jawa Barat, 2015; BPLH Kabupaten Bandung, 2015; BLH Kabupaten Sumedang, 2015; dan Greenpeace, 2015).

Banyaknya limbah cair yang dibuang oleh perusahaan-perusahan yang ada tidak sebanding dengan daya tampung dan debit air dari sungai yang dijadikan tempat dibuangnya limbah yakni Sungai Cikijing, bagian hulu di Kabupaten Sumedang dan bagian hilir di Kabupaten Bandung, oleh perusahaan-perusahaan 
yang masuk ke Kabupaten Sumedang. Menurut Kepala UPTB Laboratorium Lingkungan Hidup BLH Kabupaten Sumedang, daya tampung sungai Cikijing, untuk PT. Kahatex II yang setidaknya dalam satu hari menghasilkan debit limbah cair setidaknya 19.000 meter kubik perharinya pun sudah dapat dikatakan tidak layak.

Berlarutnya permasalahan dapat dilihat dari lahan pertanian yang tercemar semakin meluas dari 415 Ha menjadi 752 Ha (BPLHD Jawa Barat, 2015; KLHK, 2015). Berbagai upaya memang telah dilakukan sebagai bentuk respon pemerintah daerah dari mulai pengawasan hingga kesepakatan untuk penyelesaian di luar pengadilan berupa pemulihan atas lahan tercemar namun tidak menuai hasil signifikan, tidak ada kebijakan yang kemudian menjadi solusi.

Diperlukan responiveness dari Pemerintah Provinsi Jawa Barat, Pemerintah Kabupaten Bandung dan Pemerintah Kabupaten Sumedang, secara teknis dilakukan oleh badan teknis di bidang lingkungan hidup, yakni oleh Badan Pengelolaan Lingkungan Daerah (BPLHD) Provinsi Jawa Barat, Badan Pengendalian Lingkungan Hidup (BPLH) Kabupaten Bandung, dan Badan Lingkungan Hidup (BLH) Kabuaten Sumedang.

Selama kurun waktu lebih dari 20 tahun, tidak ada peningkatan kualitas atau perbaikan atas wilayah yang terkena limbah, yakni lahan petanian, malah semakin memburuk. BPLHD Provinsi Jawa Barat, BPLH Kabupaten Bandung, dan BLH Kabupaten Sumedang seolah tidak menunjukan responsiveness yang diharapkan sehingga penanggulangan dan pemulihan pencemaran limbah industri pada lahan pertanian di kawasan Rancaekek tidak berjalan sebagaimana mestinya.

Setelah mempelajari fenomena diatas dan melakukan wawancara serta obeservasi awal, peneliti menemukan beberapa indikasi masalah BPLHD
Provinsi Jawa Barat, BPLH Kabupaten Bandung, dan BLH Kabupaten Sumedang dalam penanggulangan dan pemulihan pencemaran limbah industri pada lahan pertanian di kawasan Rancaekek sebagai berikut:

1. Pencemaran di kawasan Rancaekek sejak tahun 1991, namun hingga 2016, air sungai yang merupakan sumber irigasi tetap hitam pekat dan menimbulkan bau busuk, lahan pertanian yang tetap tak produktif, lahan pertanian yang tercemar justru semakin meluas dengan trend meningkat dari tahun ke tahun.

2. Letak kawasan Rancaekek yang masuk dalam dua wilayah administratif menjadi masalah tersendiri. Terdapat perbedaan persepsi dari aspek regulasi dan aspek aparatur. Hal ini memicu perbedan sudut pandang antar aparat Badan. Kondisi ini menunjukkan adanya ego sektoral antar pemerintah daerah Kabupaten Sumedang, Kabupaten Bandung, dan Provinsi Jawa Barat, sehingga penanggulangan dan pemulihan pencemaran limbah industri pada lahan pertanian di kawasan Rancaekek berjalan lamban.

3. Kurang harmonisnya komunikasi antar Badan. Informasi yang ada di antar Badan, hanya dimiliki Badan tersebut saja, tidak ada alur informasi antar Badan, dan hanya beberapa anggota Badan saja yang mengetahui pencemaran di Kawasan Rancaekek ini.

\section{TINJAUAN TEORITIS}

Dalam penelitian ini penulis menggunakan teori responsiveness dari Igor Ansoff dan E. McDonnell (1990) yang dijabarkan lebih lanjut dalam Popescu (2014) karena terdapat relevansi dengan permasalahan yang diteliti. Permasalahan pencemaran limbah indusri di Kawasan Rancaekek tidak semata berkaitan dengan kebijakan yang ada, namun berkaitan pula dengan isu-isu yang ada, baik di lingkungan masyarakat 
maupun pemerintah, dalam merespon permasalahan tersebut, dan hal demikian relevan dengan teori yang diangkat oleh Popescu (2014) yang memandang responsiveness dapat dikaji aspek (1) climate (will to respond), (2) competence (ability to respond) and (3) capacity (volume of response).

\section{METODE PENELITIAN}

Dalam penelitian ini, penulis menggunakan metode penelitian kualitatif. Metode ini digunakan oleh penulis karena penulis ingin mengatahui secara mendalam mengapa responsiveness penanggulangan dan pemulihan pencemaran limbah industri pada lahan pertanian di Kawasan Rancaekek belum sesuai harapan, dengan menggunakan faktor-faktor penentu responsiveness, padahal permasalahannya telah berlangsung hingga lebih dari dua puluh tahun lamanya. Hal ini sesuai dengan pendapat Maxwell (1996) bahwa penelitian kualitatif merupakan penelitian yang berusaha memahami suatu makna (understanding the meaning) dalam sebuah studi mengenai peristiwa, situasi, dan perilaku serta persepektif yang terlibat di dalamnya hingga pengaruh yang ada.

Data yang diperoleh dalam penelitian ini berasal dari studi kepustakaan dan studi lapangan yang meliputi observasi, wawancara. Informan dalam penelitian ini dipilih berdasarkan teknik purposive sampling. Teknik pemeriksaan keabsahan data dalam penelitian ini adalah dengan triangulasi sumber.

\section{HASIL DAN PEMBAHASAN}

\section{Climate (Will to Respond)}

Dalam konteks penelitian ini, climate mengarah pada bagaimana suasana dan pengaruh lingkungan bagi pemerintah dalam merespon permasalahan dengan cara tertentu dan bagaimana cara meresponnya, berkenaan dengan Will to Respond dari Badan, yang dipengaruhi oleh beberapa faktor.

\subsection{Power}

Penulis menjabarkan subaspek power ke dalam bahasan regulasi, kebijakan yang dibuat, dan power serta pengaruh dari sisi nonpemerintah. Dari segi aturan, sedikitnya dalam UU 32/2009, PP 101/2014, Perda Jawa Barat 1/2012 telah diatur bahwa penanggulangan dan pemulihan lahan atas pencemaran dan/atau kerusakan lingkungan hidup, mengenai kewenangan, hingga dana jaminan.

Berdasar hasil penelitian, pemerintah pada dasarnya memiliki power untuk melakukan penanggulangan dan pemulihan pencemaran limbah industri di Kawasan Rancaekek.. Namun Pemertintah Daerah terkait belum mampu memanifestasikannya, adanya faktor lemahnya regulasi menurut aparat, sisi dilematis yang harus dihadapi, serta daya yang dimiliki perusahaan membuat responsiveness penanggulangan dan pemulihan pencemaran limbah industri pada lahan pertanian di Kawasan Rancaekek tidak sebagaimana mestinya.

\subsection{Structure}

Dalam konteks penelitian ini, subaspek structure mengarah pada bagaimana hubungan atau kolektivitas dari susunan (unit/bidang) Badan, dan unit/bidang yang menjadi representasi Badan. Berdasar wawancara didapat hasil bahwa di masing-masing Badan terdapat bidang yang memang menjadi representasi Badan, namun kurangnya kolektivitas pada tiga Badan tentu memberi pengaruh atas lambannya respon terhadap masalah penanggulangan dan pemulihan pencemaran limbah industri di Kawasan Rancaekek.

\subsection{Culture}

Dalam membahas subaspek culture penulis mengaitkannya dengan bagaimana pola dan kebiasaan Badan dalam menentukan jadwal inspeksi dan bagaimana Badan berhubungan dengan 
masyarakat dan pelaku usaha. Merujuk pada hasil wawancara dan pengamatan penulis, kebiasaan dan pola badan dalam merespon permasalahan limbah di Kawasan Rancaekek sangat normatif, menunggu hingga terjadi hal kasuistik, dan minim dalam melibatkan masyarakat.

\subsection{Mentality}

Dari keterangan informan, penulis berpandangan bahwa, terdapat ego sektoral yang cukup kentara. Terdapat missing link antara BLH Kabupaten Sumedang dan BPLH Kabupaten Bandung bahkan BPLHD Jawa Barat, namun tidak ada pembahasan atau tindak lanjut yang menghasilkan titik temu, karena tetap saling mempertahankan kepentingan sektoral mereka. Berdasar hasil penelitian didapat bahwa memang masih terdapat ego sektoral dan saling lempar tanggungjawab, sikap pasif, serta menurunnya semangat dalam penanggulangan dan pemulihan pencemaran pada lahan pertanian di Kawasan Rancaekek ini, sehingga membuat penyelesaian masalah sulit menemukan solusi dan kesatuan tindakan.

\section{Competence (Ability To Respond)}

Aspek competence mengarah pada kemampuan organisasi untuk merespon, bagaimana organisasi menyiapkan sistem, dan tentu di tentukan oleh berbagai subaspek.

\subsection{Knowledge}

Dengan mengetahui perkembangan masalah yang ada, maka dapat ditentukan dengan segera tindakan yang harus dilakukan. Pengetahuan mengenai permasalahan yang ada akan berhubungan dengan laporan dan data mengenai permasalahan tersebut. Berdasar keterangan informan dan observasi penulis, tidak banyak aparat yang mengetahui terkait permasalahan dan data-data terkait permasalahan sangat minim, sehingga merupakan hal yang wajar apabila seringkali menimbulkan perbedaan persepsi antar Badan dan tak memunculkan solusi baru dalam penanggulangan dan pemulihan lahan di Kawasan Rancaekek.

\subsection{Talent dan Skill}

Salah satu kendala yang dihadapi dalam permasalahan pencemaran limbah industri di suatu kawasan adalah munculnya anggapan kuat limbah yang terbuang bukan hanya limbah industri, namun terdapat limbah domestik seperti limbah rumah tangga. Inilah yang penulis bahas dalam subaspek talent dan skill.

Berdasar keterangan informan dan observasi penulis, sulitnya mengklasifikasi antara limbah industri dan limbah domestik bukan karena aparat tidak mampu membedakannya karena memang dapat diukur dan dapat ditentukan sesuai hitungan parameter dan baku matu. Hal yang membuat masih adanya kegamangan antara limbah industri dan limbah domestik adalah akumulasi dari limbah dibanding dengan daya tampung dan belum terpisahnya IPAL untuk industri dan untuk domestik/gabungan. Kondisi tersebut menghambat respon pemerintah

\subsection{Structure Systems}

Pembahasan subaspek structure systems mengarah pada metode, kesepakatan atau standar yang digunakan antar Badan dalam merespon permasalahan. Dengan adanya metode yang jelas dari Badan dalam merespon permasalahan akan memberikan progres dan arah yang jelas. Penelitian penunjukan hasil bahwa Badan memang tetap berpatokan pada regulasi, dari sisi Kabupaten Bandung maupun Kabupaten Sumedang mengharapkan provinsi. Sementara itu provinsi tetap mengharapkan pihak perusahaanperusahaan pelaku pencemar, padahal pada saat yang bersamaan pun mengetahui bahwa hal tersebut sulit terwujud, namun tidak ada pembahasan 
lebih lanjut mengenai penanggulangan dan pemulihan lahan ini.

Lalu Badan pun tidak terlalu konsisten dalam penyelesaian permasalahan penanggulangan dan pemulihan pencemaran limbah industri pada lahan pertanian di Kawasan Rancaekek ini, sehingga responsiveness ketiga Badan berjalan begitu saja, tanpa adanya kesepakatan dan tujuan yang diusung secara bersama dan jelas.

\subsection{Share Knowledge}

Dalam penelitian ini pun subaspek share knowledge mengarah pada bagaimana komunikasi, alur informasi, penyamaan persepsi antar Badan, hingga tindaklanjut yang dilakukan, yang merupakan hal penting karena permasalahan yang dihadapi.

Berdasar observasi dan wawancara, penulis menemukan bahwa komunikasi dan pertemuan antar Badan dalam membahas penanggulangan dan pemulihan hingga tindaklanjut yang akan dilakukan masih minim. Hal ini pun ditambah dengan tidak semua anggota ketiga Badan mengetahui permasalahan, sehingga sangat bergantung pada segelintir orang saja, dengan saat yang bersamaan permasalahan limbah industri tidak hanya di Kawasan Rancaekek.

\section{Capacity (Volume of Response)}

Kapasitas dalam penelitian ini berbicara bagaimana kemampuan dan apa yang dimiliki oleh personal dan organisasional Badan.

\subsection{Kapasitas Personal dan Organisasional}

Berdasar wawancara, secara umum mengenai kapasitas SDM aparat Badan tidak menjadi masalah bagi BPLHD Jawa Barat dan BPLH Kabupaten Bandung, bagi BLH Kabupaten Sumedang di beberapa posisi memang tidak sesuai dengan kualifikasi yang dibutuhkan. Kemudian dari segi anggaran, menurut BLH Kabupaten Sumedang, hal tersebut menjadi salah satu hambatan, selain sarana. Sementara itu BPLHD Jawa Barat menyebutkan meskipun dananya tersedia, tetap saja perusahaanlah yang seharusnya menanggung. Sedangkan BPLH Kabupaten Bandung tidak mempermasalahkan mengenai anggaran.

\section{SIMPULAN DAN SARAN}

\section{Simpulan}

Responsiveness BPLHD Jawa Barat, BPLH Kabupaten Bandung, dan BLH Kabupaten Sumedang dalam penanggulangan dan pemulihan pencemaran limbah industri pada lahan pertanian di Kawasan Rancaekek kurang baik karena belum sepenuhnya power bagi Badan berupa ketentuan perundangundangan dilaksanakan, masih kurangnya kolektivitas Badan meskipun telah ada bidang yang menjadi representasi Badan, pola penyelesaian yang hanya kasuistik, secara mentality masih adanya ego sektoral dari Badan, ditambah adanya pengaruh dari lingkungan yang menjadi sisi dilematis Badan.

Secara kualifikasi aparat Badan sudah baik, namun hanya sedikit aparat yang mengetahui permasalahan, tidak adanya structure system yang jelas dalam merespon penanggulangan dan pemulihan lahan tercemar, membuat upaya yang dilakukan lamban. Share knowledge yang kurang baik sehingga perbedaan persepsi masih sering terjadi membuat belum ditemukannya solusi pasti.

Sikap Badan yang menunggu itikad baik dari perusahaan yang tidak kunjung dirasakan pun menentukan keputusan yang diambil Badan menjadi lamban. Keterbatasan kapasitas Badan berupa anggaran, sarana dan prasarana serta dirasa kurangnya aparat secara kulitas dan kuantitas membuat responsiveness Badan tidak menunjukkan perbaikan yang jelas.

\section{Saran}

Berdasarkan hasil penelitian dan simpulan, penulis merumuskan beberapa saran yang dapat meningkatkan 
responsiveness BPLHD Jawa Barat, BPLH Kabupaten Bandung, dan BLH Kabupaten Sumedang menjadi lebih efektif. Adapun saran yang penulis berikan sebagai berikut:

1. Membuat mekanisme baku yang disepakati bersama. Dengan dibuat mekanisme atau SOP baku setiap Badan, sebagai representasi pemerintah dearah, akan memahami apa yang harus dilakukan, sehingga terdapat kejelasan progres dalam penanggulangan dan pemulihan pencemaran limbah industri pada lahan pertanian di Kawasan Rancaekek ini.

2. Membuat jadwal pengawasan dan pemantauan bersama. Dengan dibuatnya jadwal pengawasan bersama antar Badan, maka antar Badan mengetahui dengan pasti dan seksama apa yang terjadi di lapangan, terlebih permasalahan limbah industri di Kawasan Rancaekek ini merupakan permasalahan limbah industri lintas kabupaten.

3. Membentuk satgas atau pokja bersama. Dengan dibentuknya satgas atau pokja yang melibatkan ketiga Badan, maka penanggulangan dan pemulihan akan lebih intens karena memang dikoordinasikan oleh satuan yang sengaja dibentuk untuk hal tersebut, sehingga dapat menunjukan progress yang jelas.

4. Membuat jadwal pertemuan berkala. Dengan adanya pertemuan yang terjadwal, maka komunikasi antar Badan akan lebih efektif, pertukaran informasi, hingga evaluasi dapat lebih intens, hal tersebut pun dapat mereduksi ego sektoral dan ego instansi yang ada.

5. Menata ulang filing data dan laporan terkait pengendalian limbah industri di Kawasan Rancakek baik internal Badan maupun antar Badan. Hal ini dimaksudkan agar semua rekam jejak yang dilakukan menjadi bukti sekaligus menjadi acuan bagi tindakan selanjutnya, dan sebagai bahan penyamaan persepsi.

6. Mengadakan public hearing. Dengan mendengar suara masyarakat. Badan, secara luas pemerintah daerah, dapat menyusun kembali prioritas berdasarkan kebutuhan masyarakat. Disaat bersamaan ini dapat menjadi media pendekatan terhadap masyarakat yang nantinya dapat menjadi perpanjangan tangan.

\section{DAFTAR PUSTAKA \\ Buku}

Ansoff, I. dan McDonneell, E. 1990. Implanting Strategic Management. Prentice Hall. New York.

Budiardjo, M. 2008. Dasar-dasar Ilmu Politik. PT. Granedia. Jakarta.

Farazmand, Ali. 2004. Sound Governance: Policy and Public Administration Innovation. Praeger Publisher. London..

Maxwell, J. A. 1996. Qualitative Research Design: An Interactive Approach. SAGE Publications, Inc. California.

Priyarsono. 2011. Dari Pertanian ke Industri: Analisis Pembangunan dalam Perspektif Ekonomi Regional. IPB Press. Bogor.

\section{S, Pamudji. 1981. Ekologi Administrasi Negara. Bumi Aksara. Jakarta.}

Sedarmayanti. 2012. Good Governance "Kepemerintahan Yang Baik". Mandar Maju. Bandung.

\section{Jurnal}

Bryer, T.A. 2009. Explaining

Responsiveness in Collaboration: Administrator and Citizen Role Perceptions. Public Administration Review 69(2): 271-283. 
Hobolt, S. B dan Klemmenson, R. 2008. Government Responsiveness and Political Competition in Comparative Perspective. Comparative Political Studies (41): 309-337

Nawawi, J. 2012. Membangun Kepercayaan Dalam Mewujudkan Good Governance. Jurnal Ilmiah Ilmu Pemerintahan 1(3): 19-29.

Popescu, L. G. 2011. Making Public Policies Work: Between Responsiveness And Convergence Of Agendas. Transylvanian Review of Administrative Sciences (34E): 186-200

2014. Public governance and strategic responsiveness. Journal of Public Administration, Finance and Law 5: 144-156.

Saltzstein, G. H. 1992. Bureaucratic responsiveness: Conceptual issues and current research. Journal of Public Administration Research and Theory 2:63-8.

Stivers, C. 1994. The listening bureaucrat: responsiveness in public administration.

Public Administration Review 54(4): 364-369.

Sutono, S. dan Kurnia, U. 2002. Identifikasi Kerusakan Lahan Sawah Di Rancaekek Kabupaten Bandung, Jawa Barat. Peneliti Badan Litbang Pertanian Pada Balai Penelitian Tanah, Jl. Tentara Pelajar 12, Cimanggu Bogor hal 283-296.

Vigoda, E. 2000. Are You Being Served? The Responsiveness of Public Administration to Citizens Demands: An Empirical Examination in Israel Public Administration, 78(1): 165191.
. 2002. From Responsiveness

to Collaboration: Government, Citizens, and The Next Generation of Public Administration. Public Administration Review 6(5): 527 540.

\section{Peraturan Perundang-undangan}

Undang-Undang Republik Indonesia Nomor 32 Tahun 2009 Perlindungan dan Pengelolaan Lingkungan Hidup. 3 Oktober 2009. Lembaran Negara Republik Indonesia Tahun 2009 Nomor 140. Jakarta.

Peraturan Pemerintah Republik Indonesia Nomor 101 Tahun 2014 Pengelolaan Limbah Bahan Berbahaya dan Beracun. 17 Oktober 2014. Lembaran Negara Republik Indonesia Tahun 2014 Nomor 333. Jakarta.

Peraturan Daerah Provinsi Jawa Barat Nomor 22 Tahun 2010 Rencana Tata Ruang Wilayah Provinsi Jawa Barat Tahun 2009-2029. 30 November 2010. Lembaran Daerah Provinsi Jawa Barat Tahun 2010 Nomor 22 Seri E. Bandung.

Peraturan Daerah Kabupaten Bandung Nomor 3 Tahun 2008 Rencana Tata Ruang Wilayah (RTRW) Kabupaten Bandung Tahun 2007 Sampai Tahun 2027. 19

September 2008. Lembaran Daerah Kabupaten Bandung Tahun 2008 Nomor 3. Bandung.

Peraturan Daerah Kabupaten Sumedang Nomor 2 Tahun 2012 Rencana Tata Ruang Wilayah Kabupaten Sumedang Tahun 2011-2031. Sumedang.

\section{Dokumen Instansi Pemerintah}


Badan Pengendalian Lingkungan Hidup. 2015. Laporan Akhir Penyusunan Review Feasibility Study IPAL Terpadu Rancaekek Kabupaten Bandung. BPLH Kabupaten Bandung. Bandung.

Badan Pusat Statistik. 2015. Statistik Daerah Kecamatan Rancaekek, 2015. Otober.

BPS Kabupaten Bandung. Bandung.

Pemerintah Provinsi Jawa Barat. 2014. Review dan Reorientasi Satu Tahun Penanganan Multipihak Banjir Jalan Nasional Rancaekek dan Penanganan Pencemaran Limbah Industri pada Lahan Sawah. Jawa Barat.

\section{Skripsi, Tesis, Disertasi}

Ariva, P. D. 2014. Pengendalian Pencemaran Limbah Cair Industri oleh Badan Pengendalian Lingkungan Hidup (BPLH) Kabupaten Bandung (Studi: Kecamatan Rancaekek). Skripsi. Program Studi Administrasi Publik Universitas Padjadjaran. Sumedang.

Dameria, S. V. 2014. Pengendalian Pencemaran Air Sungai Di Kecamatan Majalaya oleh Badan Pengelola Lingkungan Hidup (BPLH) Kabupaten Bandung. Skripsi. Program Studi Administrasi Publik Universitas Padjadjaran. Sumedang.

Maruti, S.K. 2013. Responsivitas Pelayanan Kantor Pertanahan Kota Salatiga Dalam Implementasi Program Larasita. Tesis. Program Pascasarjana Program Studi Magister Administrasi Publik Universitas Sebelas Maret. Surakarta

\section{Artikel Seminar/symposium/diskusi}

de Silva, A. T.T. A Framework

Formeasuring Responsiveness. Gpe
Discussion Paper Series: No 32. Eip/Gpe/Ebd World Health Organization

\section{Sumber lainnya}

Koalisi Melawan Limbah. 2016. Konsekuensi Tersembunyi: Valuasi Kerugian Ekonomi Akibat Pencemaran Industri. April. Bandung

Sutono, S dan Kurnia, U. 2014. Identifikasi Kerusakan Lahan Sawah Rancaekek Kabupaten Bandung, Jawa Barat. Badan Litbang Pertanian pada Balai Penelitian Tanah. Bogor.

\section{Dalam Jaringan (internet)}

BPLHD Jawa Barat. 2015. Pengantar Diskusi FGD Bedah Kasus Pencemaran dan atau Kerusakan Lingkungan Di Kecamatan Rancaekek, Kabupaten Bandung: "Meretas Jalan Panjang Menggagpai Kebenaran dan Keadilan http://www.bplhdjabar.go.id/index.p hp/layanan/k2-categories-2/item/41pengantar-diskusi-fgd-bedah-kasuspencemaran-dan-atau-kerusakanlingkungan. 9 Januari 2016 (12.40).

Dinas Kehutanan Provinsi Jawa Barat. 2015. Limbah Pabrik Bisa Jadi Bom Waktu.

http://dishut.jabarprov.go.id/? $\bmod =$ detilBerita\&idMenuKiri=\&idBerita $=2194.9$ Januari 2016 (13.06).

Kementerian Lingkungan Hidup. 2015. Penegakanhukum Terhadap Kasus Pencemaran Lahan Pertanian Di Kecamatan Rancaekek Kabupaten Bandung. http://www.menlh.go.id/penegakanhukum-terhadap-kasus-pencemaranlahan-pertanian-di-kecamatanrancaekek-kabupaten-bandung/. 9 Januari 2016 (12. 40). 
MI, 2015. Pemrpov Gugat 3 Perusahaan Tekstil.

http://www.mediaindonesia.com/mip agi/read/10454/Pemprov-Gugat-3Perusahaan-Tekstil/2015/04/15. 10 Januari 2016 (19.10)

Nugraha, I. 2015. Sawah Tercemar Limbah Pabrik, Beginilah Nasib Petani Rancaekek. http://www.mongabay.co.id/2015/04/ 14/sawah-tercemar-limbah-pabrikbeginilah-nasib-petani-rancaekek/. 9 Januari 2016 (12.16).

Wawan. 2015. Pencemaran di Rancaekek Menggila, Siapa yang Bermain-main di Sana?.

http://pribuminews.com/14/04/2015/ pencemaran-di-rancaekek-menggilasiapa-yang-bermain-main-di-sana/. 9 Januari 2016 (14.05)

Wry. 2015. Akhirnya Menteri

Lingkungan Hidup RI Turun Langsung Sidak PT

Kahatex.

http://www.sinarpaginews.com/fullp ost/ekonomi/1400069489/akhirnya-

menteri-lingkungan-hidup-ri-turunlangsung--sidak-pt-kahatex.html. 9 Januari 2016 (12.15).

Wulandari, I. 2015. Pemkab Bandung Rugi Akibat Limbah Industri. http://m.republika.co.id/berita/nasio nal/daerah/15/04/25/nnc966pemkab-bandung-rugi-akibatlimbah-industri. 9 Januari 2016 (13.05).

Yadi, A. M. 2015. Melawan Limbah Memulihkan Sawah - bagian 1. http://m.greenpeace.org/seasia/id/hi gh/blog/melawan-limbahmemulihkan-sawah-bagian1/blog/52421/. 9 Januari 2016 (13.01). 